\title{
EVALUASI RUAS JALAN GATOT SUBROTO MENGGUNAKAN METODE IRAP UNTUK MENCAPAI STAR RATING 4 DAN 5
}

\author{
Yohanes Ryandi ${ }^{1}$ dan Ni Luh Putu Shinta Eka Setyarini \\ ${ }^{1}$ Program Studi Sarjana Teknik Sipil, Universitas Tarumanagara, Jl. Letjen S. Parman No.1 Jakarta \\ Yohanes.325160027@stu.untar.ac.id \\ ${ }^{2}$ Program Studi Sarjana Teknik Sipil, Universitas Tarumanagara, Jl. Letjen S. Parman No.1 Jakarta \\ niluhs@ft.untar.ac.id
}

Masuk: 15-07-2021, revisi: 25-08-2021, diterima untuk diterbitkan: 30-08-2021

\begin{abstract}
The rapid development of the transportation sector will indirectly increase the risk of the growth of traffic problems, one of which is traffic accidents. The number of traffic accidents in Indonesia, especially in the city of Jakarta is very high and continues to increase every year because there are still many roads that have not applied the principles of safe roads in their design and there are still many people who still choose to use private vehicles compared to public transportation. So to reduce the risk of accidents, it is necessary to carry out a strategy to improve road safety using existing methods, namely the iRAP (International Road Assessment Program) method on the Jendral Gatot Subroto road section and the results of the study obtained the existing condition of the road section, for passenger vehicles already reached 4,4, motorcycle cyclists 3,9, pedestrians 5, but for cyclists mode only 3, therefore it is necessary to do a countermeasurement to increase the Star Rating Score to 4 and 5, so that the desired star rating score is obtained on the Jalan Jendral Gatot Subroto.
\end{abstract}

Keywords: accident; IRAP; Jendral Gatot Subroto Street

\begin{abstract}
ABSTRAK
Perkembangan bidang transportasi yang cepat secara tidak langsung akan memperbesar resiko tumbuhnya permasalahan lalu lintas salah satunya adalah kecelakaan lalu lintas. Jumlah kecelakan lalu lintas di Indonesia khususnya di kota Jakarta sangatlah tinggi dan terus meningkat setiap tahunnya karena masih banyaknya ruas jalan yang belum menerapkan prinsip jalan berkeselamatan pada perancangannya dan masih banyak masyarakat yang masih memilih menggunakan kendaraan pribadi dibandingkan kendaraan umum. Maka untuk mengurangi risiko terjadinya kecelakaan, perlu dilakukan strategi peningkatan keselamatan jalan menggunakan metode yang ada, yaitu metode iRAP (International Road Assessment Programme) pada ruas jalan Jendral Gatot Subroto dan hasil dari penelitian tersebut didapatkan kondisi eksisting ruas jalan tersebut, untuk moda kendaraan berpenumpang sudah mencapai 4,4, pesepeda motor 3,9, pejalan kaki 5, tetapi untuk moda pesepeda hanya 3, maka dari itu perlu dilakukan countermeasure guna menaikan Star Rating Score menjadi 4 dan 5, sehingga didapatkan star rating score yang diinginkan pada ruas jalan Jendral Gatot Subroto.
\end{abstract}

Kata kunci: Kecelakaan; IRAP ; Jalan Jendral Gatot Subroto

\section{PENDAHULUAN}

Pertumbuhan laju penduduk di Indonesia setiap tahunnya mengalami peningkatan, menurut BPS (Badan Pusat Statistik) tercatat dalam kurun waktu sepuluh tahun terakhir (2010-2020) rata - rata pertumbuhan laju penduduk Indonesia sebesar 1,25 persen per tahun dan seiring bertambahnya penduduk memungkinkan munculnya permasalahan seperti pada bidang transportasi yaitu kecelakaan lalu lintas, hal ini terjadinya karena adanya peningkatan penggunaan kendaraan pribadi dibandingkan dengan angkutan umum yang dapat disebabkan oleh beberapa faktor, salah satunya adalah tingkat pelayanan yang ditawarkan oleh masing-masing sarana transportasi merupakan faktor yang sangat menentukan bagi seseorang dalam memilih sarana transportasi (Tamin, 2000).

Dalam hal ini, pemerintah memiliki beberapa cara untuk mengurangi angka kecelakaan lalu lintas seperti dengan penambahan ruas jalan dan meningkatkan fasilitas transportasi umum seperti pembangunan MRT (Mass Rapid Transit) di Jakarta dan saat pembangunan ini berhasil, maka masyarakat akan mempunyai pilihan trasnportasi umum yang memiliki pelayanan yang layak dan baik (Andrianysah, 2014). Karena hal tersebut sangatlah penting 
mengingat jumlah kendaraan pribadi di Jakarta adalah sekitar $84,84 \%$ dan hal ini membuat resiko terjadinya kecelakaan masih sangat tinggi (Sopandi, 2010).

Pada penelitian ini bertujuan untuk mengevaluasi keselamatan jalan di jalan Jendral Gatot Subroto dengan menggunakan metode IRAP agar dapat mencapai star rating 4 dan 5 dengan cara meneliti star rating dan memberikan masukan pada peningkatan star rating ruas jalan yang bermasalah.

\section{International Road Assessment Programme (IRAP)}

The International Road Assessment Programme (IRAP) adalah sebuah program pada bidang keselamatan jalan untuk menilai (assessment) keselamatan terhadap pengguna jalan melalui penentuan nilai atau skor risiko yang mungkin terjadi akibat dari elemen infrastruktur jalan (Highways England, 2019)

Skor tersebut adalah tingkat keparahan yang akan di derita dan gambaran peluang terjadinya kecelakaan lalu lintas. Penilaian dilakukan dengan mengidentifikasi potensi bahaya akibat defisiensi elemen jalan yang dapat mengakibatkan terjadinya kecelakaan. (Highways England, 2019)

Terdapat 4 protokol dalam iRAP, yaitu: (1) Risk mappings (peta risiko) pemetaan resiko jalan menggunakan data kecelakaan terperinci untuk menggambarkan jumlah kematian sebenarnya dan cedera pada suatu ruas jalan raya. (2) Star Rating (peringkat bintang) performa yang ditunjukkan oleh suatu ruas jalan yang akan diklasifikasikan. (3) Safer Roads Investment Plans (SRIP) pembuatan rencana star rating dari suatu ruas jalan. Untuk menaikkan star rating pada suatu ruas jalan diperlukan biaya yang eligible (terjangkau, memenuhi syarat) sehingga akan dipilih satu alternatif dari perencenaan yang terbaik. (4) Performance Tracking penelusuran dari suatu ruas jalan yang dilakukan mengulang secara terus menerus dan dievaluasi kembali.

\section{Star Rating}

Star Rating adalah metode penilaian kinerja keselamatan jalan berupa Star Rating berdasarkan kondisi elemen infrastruktur jalan. Star rating memanfaatkan data hasil inspeksi keselamatan jalan serta hubungan antara atribut jalan dan tingkat kecelakaan. Hasil akhir dari star rating merupakan bintang 1 sampai dengan bintang 5 yang dilakukan berdasarkan pengklasifikasian star rating score (SRS). Didasarkan pada data inspeksi jalan dan memberikan ukuran sederhana dan obyektif dari elemen jalan yang terpasang untuk kendaraan berpenumpang, pengendara sepeda motor, pengendara sepeda, dan pejalan kaki. Jalan dengan peringkat bintang lima adalah yang paling aman sedangkan jalan dengan peringkat bintang satu adalah yang paling tidak aman. Cara menentukan nilai star rating dapat dilihat pada Tabel 1.

- Star rating 4 dan 5 adalah jalan sudah berkeselamatan tinggi.

- Star rating 3 adalah jalan yang sudah dianggap laik fungsi

- Star rating 2 adalah jalan yang buruk dan tidak laik fungsi

- Star rating 1 adalah kondisi jalan yang paling buruk

Tabel 1. Star rating band

\begin{tabular}{cccccc}
\hline \multirow{2}{*}{$\begin{array}{c}\text { Star } \\
\text { Rating }\end{array}$} & \multicolumn{5}{c}{ Star Rating Score } \\
\cline { 2 - 6 } & $\begin{array}{c}\text { Vehicle occupants and } \\
\text { motorcyclists }\end{array}$ & Bicyclists & \multicolumn{3}{c}{ Pedestrians } \\
\cline { 3 - 6 } & 0 to $<2,5$ & 0 to $<5$ & 0 to $<5$ & 0 to $<0,2$ & 0 to $<4,8$ \\
4 & 2,5 to $<5$ & 5 to $<10$ & 5 to $<15$ & 0,2 to $<1$ & 4,8 to $<14$ \\
3 & 5 to $<12,5$ & 10 to $<30$ & 15 to $<40$ & 1 to $<7,5$ & 14 to $<32,5$ \\
2 & 12,5 to $<22,5$ & 30 to $<60$ & 40 to $<90$ & 7,5 to $<15$ & 32,5 to $<75$ \\
1 & $22,5+$ & $60+$ & $90+$ & $15+$ & $75+$
\end{tabular}

(Sumber: iRAP Methodology Fact Sheet 7: Star Rating Bands, Drive on Left Edition)

\section{Star Rating score equation}

Nilai SRS dihitung sesuai jalan yang diteliti yaitu di bagi setiap segmen jalan sepanjang $100 \mathrm{~m}$. Nilai tersebut dapat memperhitungkan jenis kecelakaan yang ada pada setiap segmen yang diteliti. Lalu hasil hitungan disesuaikan seperti pada tabel 1 . 


\section{Countermeasure}

Countermeasure adalah salah satu bagian dari bagian penanganan meotde iRAP yaitu Safer Road Invesment Plan dengan tujuan untuk meningkatkan star rating awal eksisting jalan yang diinginkan dan dapat mengurangi risiko kematian dan cedera serius. Countermeasure dilakukan dengan cara melakukan perubahan elemen- elemen jalan yang tersedia sebanyak 94 penanganan yang ditetapkan IRAP.

\section{Casualty estimation and calibration}

Dilakukan pencarian Fatalities Serious Injuries (FSI) setelah dilakukan treatment dengan menggunakan rumusrumus.

\section{Economic assessment}

Analisis ekonomi dilakukan dalam metodologi IRAP untuk mengoptimalkan tindakan pencegahan. Analisis ekonomi dilakukan dua kali selama penilaian IRAP Selama proses pemilihan countermeasure, setiap tindakan penanggulangan di setiap segmen jalan sepanjang 100 meter harus menghasilkan Benefit Cost Ratio (BCR) yang didapatkan harus optimal sehingga penanggulangan layak untuk dimasukkan dalam Safer Road Investment Plan (SRIP) pada periode 20 tahun atau lebih.

\section{METODE PENELITIAN}

\section{Tahap studi pustaka}

Pada tahap ini peneliti melakukan studi pustaka, yaitu memperdalam pengetahuan mengenai metode IRAP melalui pembacaan tentang studi terdahulu dan jurnal-jurnal yang terkait. Selanjutnya melakukan pengumpulan data-data pendukung mengenai kondisi ruas jalan yang akan di teliti yaitu ruas jalan Jendral Gatot Subroto dan dari data yang terkumpul harus dapat kredibilitas hasil penelitian yang dilakukan.

\section{Tahapan pengambilan data primer}

Pada tahap pengambilan data primer, peneliti memilih menggunakan bantuan aplikasi Google Street View dan Google Earth View untuk mengamati kondisi eksisting ruas Jalan Jendral Gatot Subroto.

\section{Tahapan pengambilan data sekunder}

Pada tahap ini, peneliti akan mengambil data sekunder dari ruas jalan Jendral Gatot Subroto.Data yang diperlukan adalah Lalu Lintas Harian Rata-Rata (LHR), data kecelakaan, dan Rancangan Anggaran Biaya (RAB). Data LHR didapat dari Instansi terakit yaitu Dinas Perhubungan DKI Jakarta, data kecelakaan didapat dari Badan Pusat Statistik Provinsi DKI Jakarta dan data RAB didapat dari Balai Besar Pelaksanaan Jalan Nasional VI (BBPJN VI) (DKI Jakarta, Jabar dan Banten), yang diperlukan untuk mencari star rating score.

\section{Tahap coding}

Setelah dilakukan survey ruas jalan melalui Google Stree View serta pengumpulan sekunder dan primer, Langkah selanjutnya pada penelitian ini adalah melakukan coding untuk mendapatkan star rating awal. Coding attributes mengikuti IRAP Coding Manual Drive on Left Edition 2019.

\section{Tahap Rating Score awal}

Pada Tahap ini, akan mendapatkan Rating Score awal dihitung dengan metode SRS Equation untuk setiap 100 meter segmen jalan dan masing-masing dari empat pengguna jalan akan menghasilkan Star Rating Score yang dapat menilai kondisi eksisting ruas Jalan Jendral Gatot Subroto.

\section{Tahapan mengevaluasi atribut yang dinilai bermasalah}

Melakukan evaluasi terhadap elemen-elemen pada jalan yang menjadi permasalahan keselamatan pengguna jalan agar dapat meningkatkan star rating pada ruas jalan Jendral Gatot Subroto. Tersedia 94 macam penanganan yang tersedia pada IRAP yang telah terbukti Benefitnya.

\section{Trial and error}

Pada tahap ini dilakukan proses trial and error agar dapat melihat kombinasi treatment yang paling cocok dan logis untuk dilakukan pada ruas jalan / segmen yang bermasalah. 


\section{Tahap menghitung biaya alternatif serta $B C R$}

Melakukan penghitungan biaya alternatif terhadap perubahan elemen-elemen pada jalan serta tahap analisis BCR yang merupakan analisis untuk mengetahui keuntungan/kerugian serta kelayakan suatu proyek sehingga dapat dimasukan ke SRIP.

\section{Tahap Rating Score akhir}

Setelah dilakukan tahap menghitung biaya alternatif serta BCR terhadap perubahan elemen-elemen pada atribut jalan yang telah dilakukan. Pada tahap ini, akan mendapat hasil akhir Star Rating dari ruas Jalan Jendral Gatot Subroto.

\section{Tahap hasil analisis data}

Dilakukan audit hasil pengamatan yang sebelumnya sudah dilaksanakan dengan observasi langsung pada Jalan Jendral Gatot Subroto dengan menggunakan formulir Audit Keselamatan Jalan. Sehingga apabila hasil audit yang dihasilkan tidak sesuai dengan standar yang berlaku di Indonesia, dapat dilakukan perbaikan agar dapat mengurangi frekuensi terjadinya kecelakaan.

\section{Kesimpulan dan saran}

Pada tahap kesimpulan dan saran maka peneliti akan memberikan kesimpulan dan saran terkait dengan hal-hal apa saja dari penelitian ini yang dapat meningkatkan keselamatan lalu lintas.

\section{HASIL DAN PEMBAHASAN}

\section{Coding hasil survei kondisi eksisting Ruas Jendral Gatot Subroto}

Data yang diperoleh dari survei melalui bantuan Google Street View dan Google Maps akan di coding untuk mendapatkan faktor resiko elemen-elemen jalan eksisting ruas jalan Jendral Gatot Subroto. Proses coding dilakukan untuk setiap 100m segmen jalan. Tabel 2 merupakan contoh coding untuk 5 atribut jalan dan faktor resiko dari jalan eksisting Segmen 1. Contoh coding atribut jalan dapat dilihat pada Tabel 2.

Tabel 2. Contoh coding atribut untuk mendapatkan faktor resiko Vehicle Occupant

\begin{tabular}{cccc}
\hline No. & Attributes & Category & Vehicle occupant \\
\hline 1 & Lane Width & Medium $(\geq 2,75 m$ to $<3,25 m)$ & 1,05 \\
2 & Curvature & Straight or gently curving & 1 \\
3 & Quality of Curve & Adequate & 1 \\
4 & Delineation & Adequate & 1 \\
5 & Shoulder rumble strips & Not present & 1,2 \\
\hline
\end{tabular}

\section{Rating Score awal}

Untuk memperoleh Rating Score awal pada masing-masing segmen jalan, maka digunakan rumus perhitungan SRS. Perhitungan SRS dilakukan pada setiap segmen jalan atau setiap 100m dan dilakukan pengklasifikasian berdasarkan berdasarkan moda pengguna jalan, yaitu mobil, sepeda motor, sepeda dan pejalan kaki. Nilai SRS disesuaikan dengan tingkat resiko, apabila nilai SRS tinggi maka nilai resikonya juga tinggi yang mengakibatkan peringkat bintang/star rating jalan tersebut rendah.

Dari hasil perhitungan persamaan SRS untuk vehicle occupant, motorcyclist, pesepeda dan pejalan kaki hasil rating score lalu dikonversi ke rentang nilai star rating bands untuk masing-masing pengguna jalan. Hasil rekapitulasi semua segmen ditunjukan pada Tabel 3. 
Tabel 3. Rekapitulasi Star Rating pada lajur lambat Jalan Jendral Gatot Subroto

\begin{tabular}{cccccccccccc}
\hline $\begin{array}{c}\text { Pengguna } \\
\text { Jalan }\end{array}$ & 0,0 & 0,1 & 0,2 & 0,3 & 0,4 & 0,5 & 0,6 & 0,7 & 0,8 & 0,9 & $\begin{array}{c}\text { Rata- } \\
\text { rata }\end{array}$ \\
\hline Mobil & 5 & 5 & 5 & 5 & 5 & 5 & 5 & 4 & 5 & 5 & 4,9 \\
Motor & 4 & 4 & 4 & 4 & 4 & 4 & 4 & 3 & 4 & 4 & 3,9 \\
Pesepeda & 3 & 3 & 3 & 3 & 3 & 3 & 3 & 3 & 3 & 3 & 3 \\
Pejalan Kaki & 5 & 5 & 5 & 5 & 5 & 5 & 5 & 5 & 5 & 5 & 5 \\
\hline
\end{tabular}

Pada segmen 1 sampai dengan 10, didapat hasil star rating kondisi eksisting jalan pada vehicle occupant dan pedestrian, bernilai diatas atau sama dengan 4, berarti kondisi eksisting jalan Jendral Gatot Subroto untuk kendaraan berpenumpang dan pejalan kaki pada ruas jalan yang diteliti sudah berkesalamatan tinggi. Sedangkan untuk pesepeda dan kendaraan sepeda motor masih memiliki nilai star rating 3, untuk pesepeda sepanjang 1 kilometer, sedangkan untuk sepeda motor pada segmen 0,7 , menandakan bahwa ruas jalan tersebut perlu diadakan treatment untuk mencapai star rating yang diinginkan.

\section{Countermeasure}

Countermeasure untuk meningkatkan star rating menjadi bintang 3 melalui opsi penanganan yang ada. Untuk penanganan yang dipilih adalah rambu pesepeda, rambu batas kecepatan, dan rambu di persimpangan. Tabel 4 adalah contoh penangulangan pada pesepeda yang menunjukan fatal and injury saved jika dilakukan penanganan ini.

Tabel 4. Countermeasure untuk pesepeda

\begin{tabular}{ccccc}
\hline Treatment & $\begin{array}{c}\text { Faktor resiko } \\
\text { sebelum }\end{array}$ & $\begin{array}{c}\text { Faktor resiko } \\
\text { sesudah }\end{array}$ & $\begin{array}{c}\text { Efektifitas } \\
(\%)\end{array}$ & $\begin{array}{c}\text { FSI } \\
\text { Saved }\end{array}$ \\
\hline Rambu batas kecepatan $40 \mathrm{~km} / \mathrm{h}$ & 1,25 & 1 & 20 & 3,9032 \\
Rambu sepeda & 20 & 19 & 5 & 0,9758 \\
Pemasangan marka batas lajur & 1,2 & 1 & 16.67 & 3,2533 \\
\hline
\end{tabular}

\section{Economic assessment}

Economic Assessment ini diawali dengan perhitungan biaya alternatif terhadap perubahan-perubahan pada elemen jalan yang sudah dihitung. Perhitungan biaya penanganan juga harus optimal dengan anggaran terbatas agar dapat dimasukan kedalam SRIP. Perhitungan BCR digunakan untuk mengetahui apakah biaya untuk penanganan optimal atau tidak. Benefit/keuntungan penanganan yang didapat dari perhitungan adalah reduksi pada FSI yang dihitung sebelumnya dapat dilihat pada Tabel 5.

Tabel 5. Benefit Cost Ratio pada penanganan selama 20 tahun

\begin{tabular}{cccc}
\hline Countermeasure & Cost (IDR) & Benefit (IDR) & BCR \\
\hline Rambu pesepeda & 202.742 .680 & 8.551 .521 .614 & 42,1792 \\
Rambut batas kecepatan 40 km/h & 55.293 .460 & 34.206 .086 .000 & 618,628 \\
Marka pembatas Lajur & 14.075 .000 & 28.510 .773 .000 & 2025,68 \\
Total & 272.111 .140 & 7.126 .838 .061 .614 & 2686,4872 \\
\hline
\end{tabular}

Perhitungan BCR untuk penanggulangan yang dilakukan menunjukan bahwa semua penanganan yang dilakukan menguntungkan pada 20 tahun kedepan sesuai dengan rekomendasi dari IRAP. Pada Tabel 5 menunjukan countermeasure membutuhkan anggaran sebesar IDR 272.111.140 untuk periode 20 tahun yang akan menghasilkan keuntungan dari pengurangan kecelakaan yang telah dihitung sebesar IDR 7.126.838.061.614. Hasil BCR sebesar 2686,4872 untuk semua penanganan. Dengan hasil benefit/cost diatas 1, maka penanggulangan ini layak.

\section{Rating Score akhir}

Untuk memperoleh rating score akhir pada masing-masing segmen jalan, maka digunakaan elemen-elemen jalan yang telah dilakukan countermeasure untuk masing-masing segmen jalan sesuai dengan sesuai dengan perhitungan SRS. Perhitungan SRS (Star Rating Score) dilakukan pada setiap segmen jalan atau setiap 100m dan dilakukan 
pengklasifikasian berdasarkan masing-masing pengguna jalan, yaitu penumpang kendaraan, pengendara sepeda motor, pengendara sepeda, dan pejalan kaki.

Setelah didapat nilai SRS untuk masing-masing pengguna jalan untuk setiap 100 meter segmen jalan, maka untuk menentukan star rating untuk tiap segmen jalan, nilai SRS dialokasikan ke rentang nilai star rating bands untuk masing-masing pengguna jalan. Rekapitulasi data star rating awal ditunjukan pada Tabel 6.

Tabel 6. Rekapitulasi Star Rating akhir untuk Jalan Jendral Gatot Subroto

\begin{tabular}{cccccccccccc}
\hline $\begin{array}{c}\text { Pengguna } \\
\text { Jalan }\end{array}$ & 0,0 & 0,1 & 0,2 & 0,3 & 0,4 & 0,5 & 0,6 & 0,7 & 0,8 & 0,9 & $\begin{array}{c}\text { Rata- } \\
\text { rata }\end{array}$ \\
\hline Mobil & 5 & 5 & 5 & 5 & 5 & 5 & 5 & 5 & 5 & 5 & 5 \\
Motor & 4 & 4 & 4 & 4 & 4 & 4 & 4 & 4 & 4 & 4 & 4 \\
Pesepeda & 4 & 4 & 4 & 4 & 4 & 4 & 4 & 4 & 4 & 4 & 4 \\
Pejalan & 5 & 5 & 5 & 5 & 5 & 5 & 5 & 5 & 5 & 5 & 5 \\
Kaki & 5 & & & & & & & & & &
\end{tabular}

Tidak dapat dilakukan pelabaran jalan untuk menambahkan fasilitas pesepeda, dikarenakan Jalan Jendral Gatot Subroto berada pada tengah kota sehingga sulit untuk dilakukan pelebaran trotoar. Untuk itu star rating pesepeda hanya sebesar 3. Setelah dilakukan penambahan rambu penyebrangan pada persimpangan, nilai star rating pejalan kaki pada segmen dan 0,7 meningkat menjadi 4.

\section{KESIMPULAN DAN SARAN}

\section{Kesimpulan}

Berdasarkan hasil dari analisis metode iRAP didapatkan Nilai star rating eksisting pada ruas Jalan Jendral Gatot Subroto sebesar 4,9 untuk vehicle occupant, 3,9 untuk motorcyclist, 3 untuk bicyclist, dan 5 untuk pedestrian. Pada motorcyclist terdapat permasalahan di segmen 0,7 dan untuk bicyclist sepanjang $1 \mathrm{~km}$.

Setelah dilakukan 8 kali trial and error dipilih trial and error 3 karena merupakan kombinasi treatment yang paling cocok untuk dilakukan, yaitu penambahan rambu pesepeda, rambu batas kecepatan dan marka pembatas jalan. Setelah di lakukan treatment terjadi peningkatan score rating akhir dari 4,9 menjadi 5 untuk vehicle occupant, 3,9 menjadi 4 untuk motorcyclist, walaupun pada bicyclist tidak menaikan score rating karena treatment yang dilakukan adalah penambahan rambu pesepeda pada ruas jalan dan rambu batas kecepatan.

Nilai BCR pada ruas jalan Jendral Gatot Subroto setelah diterapkan treatment yang dihasilkan oleh metode iRAP adalah Rambu batas kecepatan sebesar 618,628, rambu sepeda sebesar 42,1792 dan marka pembatas lajur sebesar 2025,68, semua treatment yang dilakukan melebihi angka 1 yang berarti perbaikan atribut layak dilakukan. Dari treatment yang dilakukan dapat mencegah jumlah kematian sebesar 11 nyawa dan jumlah luka berat sebesar 70 nyawa.

\section{Saran}

Sebelum penelitian menggunakan iRAP di lakukan, lebih baiknya menerjemahkan materi iRAP menggunakan Google Translate agar lebih memahami metodologinya dan juga membaca reverensi dari penelitian terdahulu. Pada saat proses coding dan perhitungan star rating score sebaiknya di lakukan dengan teliti sehingga terhindar dari hasil akumulasi yang salah.

\section{DAFTAR PUSTAKA}

Andrianysah. (2014). Manajemen Transportasi Dalam Kajian dan Teori Fakultas Ilmu Sosial dan Ilmu Politik Universitas Prof.Dr.Moestopo Beragama. Jakarta.

Badan Pusat Statistik (BPS). (2020). Hasil sensus penduduk 2020.

Highway England. (2019). The strategic road network star rating report. United Kingdom.

Sopandi. (2010). Identifikasi Karakteristik Pergerakan Penduduk Dengan Maksud Bekerja. Bandung.

Tamin, Z.Ofyar. (2000). Perencanaan dan Permodelan Transportasi. Bandung. 